\title{
Model for comparative assessment of commercial seaports in global transport and logistics infrastructure
}

\author{
Roman S. Marchenko \\ Graduate School of Business and \\ Management \\ Peter the Great St.Petersburg \\ Polytechnic University \\ St. Petersburg, Russia \\ marchenko_rs@spbstu.ru \\ Tatyana N. Saurenko \\ Department of trade and merchandising \\ 2Peoples Friendship University of \\ Russia (RUDN University) \\ St. Petersburg, Russia \\ s_uvarov@mail.ru
}

\author{
Vladimir G. Anisimov \\ Graduate School of Business and \\ Management \\ Peter the Great St.Petersburg \\ Polytechnic University \\ St. Petersburg, Russia \\ an-33@yandex.ru
}

\author{
Evgenyi G. Anisimov \\ Department of Customs Operations and \\ Customs Control \\ Russian Customs Academy \\ St. Petersburg, Russia \\ mihalchevski_uu@spbguga.ru
}

\begin{abstract}
The main direction of economic development is the digitalization of business processes. It covers all sectors of the economy. The peculiarity of the current stage of digitalization is the expansion of its functional space, the universal transition from digitalization in the field of information exchange to digitalization of management of individual economic processes, as well as sectors of the economy and the economy as a whole. At the same time, the digitalization of management implies the availability of tools for forming managerial decisions. Such tools, in particular, are mathematical models. The development of such a model for the comparative assessment of commercial seaports in the global transport and logistics infrastructure is the purpose of this article.
\end{abstract}

The model is based on the presentation of commercial seaports as vectors of their technological and economic parameters. Comparison of ports is provided by additive or multiplicative scalarization of these vectors taking into account the needs of participants of transport and logistics processes. Their needs, i.e. the purposes of comparing ports, are formalized by establishing the importance coefficients of technological and economic parameters for the participants of transport and logistics processes. Since participants in these processes are usually unable to directly quantify the importance coefficients, there is uncertainty. The article adopts a probabilistic interpretation of this uncertainty. The establishment of coefficients of relative importance of specific indicators of commercial seaports is based on the principle of maximum uncertainty. The second kind of entropy is taken as the measure of uncertainty. It has allowed to receive simple enough relations for an establishment of quantitative values of considered factors of importance.

The proposed approaches are the basis for the creation of specific models and techniques in the interests of the participants of transport and logistics processes to justify a wide range of management decisions. In particular, they can be used to justify decisions on the development of logistics infrastructure of commercial seaports, as well as to attract investment in its development.

Keywords - transport and logistics infrastructure, commercial seaports, comparative analysis, justification of management decisions, modeling.

\section{INTRODUCTION}

From a transport and logistics perspective, the modern world represents a unified system connected by a transport and logistics network [1 - 4]. Elements of this network are transport nodes and transport routes connecting them. A special place in the system of transport nodes is occupied by sea trading ports. Them, like other elements of the global transport and logistics network, perform interrelated economic and technological functions. From the point of view of technology, the special place of commercial seaports is due to the fact that they are often the only nodes connecting the sections of the transport and logistics network. At the same time, they combine sea transport routes with rail, road, river and sometimes air routes, and also provide an opportunity to conduct a wide range of cargo operations [5].

From an economic perspective, commercial seaports are large economic entities that bring a significant part of the value added to the goods transported through them. Each port aims to increase its profit. The volume of profit is determined by the volume and variety of cargo transported through the port, as well as the spectrum and volume of operations carried out with them in the port. Therefore, commercial seaports compete with each other, struggle for cargo carriers and, 
within the framework of this struggle, develop their infrastructure and expand the range of services provided to carriers [6]. The high cost of these measures leads to the need for their careful justification. In particular, models of comparative assessment of commercial seaports are a tool of such substantiation.

Shippers, in the struggle for their profits, also compare ports by different indicators and choose the most preferable ones. At the same time, increasing the intensity of traffic, increasing the volume and variety of goods transported, and expanding the range of points of origin and destination make comparison a non-trivial task. It requires the use of appropriate tools. Such tools are models for comparative assessment of commercial seaports.

Other participants of transport and logistics processes such as: cargo owners, consignors, consignees, owners of terminals and warehouses, insurance, agency, stevedoring, talmanian and consulting companies and associations of surveyors are also interested in objective comparative assessment of sea trade ports.

Therefore, the management bodies of commercial seaports, freight forwarding companies and other participants in transport and logistics processes objectively need models that provide a comparative assessment of commercial ports [7]. The development of an approach to the construction of such models is the purpose of this article.

\section{VERBAL PRESENTATION OF COMPARATIVE ASSESSMENT MODELS FOR COMMERCIAL SEAPORTS}

Commercial seaports, as objects of comparative assessment, are complex infrastructure complexes combining sea and shore-based facilities.

Technological characteristics of the commercial seaport water area include the size of the water area and its parts, depth in the port, port line mark, length of the quay line, etc. These characteristics determine: conditions of safe entry, maneuvering and approach of ships to berths; convenience and safety of berthing and waiting on the move of transport vessels; convenience of port fleet and technical facilities during cargo and passenger operations; conditions of supply and servicing of vessels [8].

The main onshore facilities of commercial seaports include technological transshipment complexes (TTCs). They represent a set of engineering structures and technical means ensuring safe approach of cargo ships, their mooring, mooring, parking, loading and unloading of cargo.

The characteristics of the TTC and the water area determine the specifics and potential throughput capacity of the commercial seaport. At the same time, when making a comparative assessment of commercial seaports, it is necessary to take into account not only their potential, but also the situation in the global market of transport and logistics services [9]. This situation with regard to commercial seaports is characterized:

- the presence and severity of competition between existing ports;

- the volume of "Hinterland", i.e. the economic region adjoining the port;
- the possibility of redirecting cargo flows to and from Hinterland;

- the ability of port clients to switch to other global resources and markets that influence the level of port activity;

- the extent to which individual carriers dominate the port services market and the influence of port service providers.

Thus, the overall comparative assessment of commercial seaports in global transport and logistics infrastructure is linked to the need to take into account a significant number of different factors (port characteristics). These factors are of different nature, measured on different scales, and affect the position of the port in the global transport and logistics infrastructure to varying degrees. The aim of the comparison is to establish, on the basis of these factors, integrated indicators of the conformity of ports with the needs of certain participants in transport and logistics processes. In general, this task is nontrivial and quite complicated. Its correct solution is not possible without appropriate formalization.

\section{FORMALIZED PRESENTATION OF THE COMPARATIVE ASSESSMENT MODEL FOR COMMERCIAL SEAPORTS}

In the interest of comparative assessment, available information on comparable commercial seaports can be easily provided in the form of appropriate vectors

$$
W_{j}=\left\|w_{i}(j)\right\|, \quad j=1,2, \ldots, J, \quad i=1,2, \ldots, I,
$$

where $\mathrm{J}$ is the number of commercial seaports to be compared;

$j$ - trade port identifier;

$I$ - number of specific indicators characterizing each of the compared merchant seaports;

$i$ - port index identifier;

$w_{i}(j)$ - Assessment of the $\mathrm{i}$-th component of the vector (i-th factor) of the $j$-th commercial seaport.

It is assumed that each component of the $w_{i}(j)(i=1,2, \ldots, \mathrm{I})$ vector (1) for all ports is measured on a single scale.

In such an information situation from the mathematical point of view, the task of establishing the degree of conformity of ports to the needs of certain participants of transport and logistics processes on the basis of known factors is the task of comparing vectorial values [10]. Its solution for the general case is possible only by means of reduction of the totality of indicators characterizing commercial seaports to some generalized (integral) indicator. That is, the comparative assessment of trade seaports is the formation of a certain scalar function of the vector argument on the selected set of indicators [11]:

$$
q(j)=q\left[w_{i}(j)\right], \quad j=\overline{1, J}, \quad i=\overline{1, I},
$$

I is the number of specific indicators that characterize each of the merchant seaports being compared;

The generalized indicator (2) makes it possible to organize commercial seaports by the value $\mathrm{q}(\mathrm{j})$ and to identify the best 
(in the sense of the maximum criterion of this indicator) variant.

The type of function $q(j)$ is determined by how the contribution of each indicator to the aggregate is modelled. The functions of additive (2) or multiplicative (3) types are usually used:

$$
\begin{gathered}
q(j)=\sum_{i=1}^{I} P_{i} S_{i}(j), \quad j=\overline{1, J}, \\
q(j)=1-\prod_{i=1}^{I}\left[1-P_{i} S_{i}(j)\right], \quad j=\overline{1, J},
\end{gathered}
$$

where $\operatorname{Si}(\mathrm{j})$ is the value of $\mathrm{i}$-th $(\mathrm{i}=1,2, \ldots, \mathrm{I})$ vector component (1) of the vector component of the $j$-th commercial seaport reduced to a single scale of assessment;

Pi- coefficient of relative importance for the participant of the transport and logistics process of the corresponding particular characteristic of the compared sea commercial ports;

$$
\sum_{i=1}^{I} P_{i}=1
$$

The relationships (3) and (4) are essentially different representations of the comparative assessment model for commercial seaports. Their specification is provided by a constructive definition of $\mathrm{Pi}$ and $\mathrm{Si}(\mathrm{j})(\mathrm{i}=1,2, \ldots, \mathrm{I}, \mathrm{j}=1,2, \ldots, \mathrm{J})$. The choice of $\mathrm{Pi}$ values $(\mathrm{i}=1,2, \ldots, \mathrm{I})$ is determined by the purposes of comparative assessment of commercial seaports, and $\operatorname{Si}(j)(i=1,2, \ldots, I, j=1,2, \ldots, J)$ are obtained by bringing the values of vector components (1) to a single scale of assessments.

To determine $\operatorname{Si}(\mathrm{j})$, a reference port must be selected. It is reasonable to use a reference port as a reference port, which has the highest values of indicators characterizing the ports being compared, i.e:

$$
w_{i}^{*}(j)=\max _{i, j} w_{i}(j), i=\overline{1, I}, j=\overline{1, J} .
$$

Then each commercial seaport can be characterized by values relative to the reference port:

$$
S_{i j}^{*}=\frac{w_{i}(j)}{w_{i}^{*}(j)}, \quad i=\overline{1, I}, j=\overline{1, J} .
$$

Let's enter the parameters of the $d_{i j}$, such that:

$$
d_{i j}=\left\{\begin{array}{l}
1, \quad \text { if increasing } S_{i j}^{*} \text { increases the port's } \\
\text { preference, then } \\
0-\text { otherwise }
\end{array}\right.
$$

Than every seaport could be characterized by the values

$$
S_{i}(j) \quad i=1,2, \ldots, I, \quad j=1,2, \ldots, J,
$$

such that:

$$
S_{i}(j)=\left\{\begin{array}{c}
S_{i j}^{*} \text { at } d_{i j}=1, \\
1-S_{i j}^{*} \text { at } d_{i j}=0 .
\end{array}\right.
$$

This way of converting the indicators of comparable commercial seaports to a single scale ensures, firstly, that the aggregate indicator $\mathrm{q}(\mathrm{j})$ is dimensionless, while private indicators may have different dimensions and, secondly, that the condition necessary for the correctness of the ratio (4) is met.

The values of $\mathrm{Pi}(\mathrm{i}=1,2, \ldots, \mathrm{I})$ are determined by the objectives of the comparative assessment of commercial seaports. At the same time, participants in the transport and logistics process, as a rule, cannot directly establish their quantitative values, i.e. there is uncertainty. At probabilistic interpretation of this uncertainty, the establishment of coefficients of relative importance of specific indicators of commercial seaports may be based on the principle of maximum uncertainty $[9,10]$. The expediency of its application is due to the fact that the available information does not allow for the analysis of commercial seaports:

1) to determine the exact value of relative importance of an indicator in all possible conditions of the transport and logistics process;

2) to define accurately the probability distribution law of the relative importance of commercial seaport indicators.

Therefore, of all possible variants of the probability distribution law, the most sustainable one should be chosen. Such a variant is the distribution law, characterized by the maximum value of the uncertainty measured by entropy, which remained after using all objective information available to the decision-maker. This type of probability distribution law is based on a minimum of speculation. Therefore, it is the most objective in the respective information situation $[12,13]$.

Based on the experience of comparative assessment of commercial seaports, the practical possibilities of analyzing the weights under consideration $(\mathrm{i}=1,2, \ldots, \mathrm{I})$ are limited by their paired comparison. As a result of the comparison, some linear relations of the order can be established on the set $P=\left\{P_{i}\right\}, \quad(i=1,2, \ldots, I) \quad$ of the considered coefficients. Therefore, in the real information situation the task of determining the numerical values of $i=1,2, \ldots, I$ is to establish the method of converting the preferences given in the form of the formed order relations into the corresponding point estimates.

A convenient method of such transformation in the interests of the problem of determining the coefficients of relative importance of specific indicators of commercial seaports is the use of the models proposed by Fishburn [14] for a priori obtaining of linear limits of point estimates of probabilities of events not contradicting some system of linear limitations.

The expediency of these models is due to the fact that the establishment of relations of order on the set of coefficients $P=\left\{P_{i}\right\}, \quad i=1,2, \ldots, I$ is one of the simplest and most natural operations of analysis of sea trade ports, corresponding to the real activity of the participants of the transport and logistics process. In this case, in the information situation under consideration, the level of uncertainty should be evaluated on the basis of the use of the second type of entropy 


$$
H\left(P_{i}\right)=\prod_{i=1}^{I} P_{i}^{I-i+1} .
$$

Then the model of the problem of determining the numerical values of $i=1.2, \ldots, I$ takes the following form [15]

$$
\begin{gathered}
H\left(P_{i}\right)=\prod_{i=1}^{I} P_{i}^{I-i+1} \underset{\left\{P_{i}: L\left(P_{i}\right)\right\}}{\longrightarrow} \max , \\
\sum_{\substack{i=1 \\
I}}^{I} P_{i}=1,
\end{gathered}
$$

where $\left\{P_{i}: L\left(P_{i}\right)\right\}$ - means that the values of $\mathrm{i}=1,2, \ldots, \mathrm{I}$ satisfy the linear order relation.

It can be shown that if the different characteristics of each port are equal, that is, if the order is relevant $P_{1}=P_{2}=\ldots=P_{I}$, the most stable of these is the uniform distribution of the entropy, i.e. the most stable. Taking into account this value $\mathrm{i}=1,2, \ldots, \mathrm{I}$ are determined by the formula

$$
P_{i}=\frac{1}{I}, \quad i=1,2, \ldots, I
$$

When establishing for the elements of the set $P=\left\{P_{i}\right\}, \quad i=1,2, \ldots, I$ a simple linear relation of the order $L\left(P_{i}\right): P_{1} \geq P_{2} \geq \ldots \geq P_{I}$ rom the solution of the problem (7) - (9) it follows that the weights $P_{i}, \quad i=1,2, \ldots, I$ are calculated by the formula

$$
P_{i}=\frac{2(I-i+1)}{I(I+1)}, \quad i=1,2, \ldots, I .
$$

When establishing a strict order relation for the elements of the set $P=\left\{P_{i}\right\}, \quad i=1,2, \ldots, I$ elements of the set $L\left(P_{i}\right): \quad P_{1}>P_{2}>\ldots>P_{I}, \quad$ it follows from the solution of the problem (7) - (9) that the weight $P_{i}, \quad i=1,2, \ldots, I$ are calculated by the formula

$$
P_{i}=\frac{I-i+2}{I 2^{i}}, \quad i=1,2, \ldots, I .
$$

When setting the elements to a set of $P=\left\{P_{i}\right\}, \quad i=1,2, \ldots, I$ of an enhanced linear order of magnitude $\quad L\left(P_{i}\right): \quad P_{i} \geq \sum_{n=i+1}^{I} P_{n}, \quad i=1,2, \ldots, I$, from the solution of problem (7) - (9) it follows that the values of the weight coefficients can be taken as point estimates

$$
P_{i}=\frac{2^{I-i}}{2^{I}-1}, \quad i=1,2, \ldots, I .
$$

\begin{tabular}{|c|c|c|c|c|c|}
\hline \multirow{2}{*}{$\begin{array}{c}\text { Type of relationship } \\
\text { order }\end{array}$} & \multicolumn{5}{|c|}{ Weights } \\
\hline & P1 & $\mathrm{P} 2$ & P3 & $\mathrm{P} 4$ & P5 \\
\hline$P_{1}=P_{2}=\ldots=P_{I}$ & 0.200 & 0.200 & 0.200 & 0.200 & 0.200 \\
\hline$P_{1} \geq P_{2} \geq \ldots \geq P_{5}$ & 0.333 & 0.267 & 0.200 & 0.133 & 0.067 \\
\hline$P_{1}>P_{2}>\ldots>P_{5}$ & 0.600 & 0.250 & 0.100 & 0.038 & 0.012 \\
\hline$P_{i} \geq \sum_{n=i+1}^{I} P_{n}, \quad i=1,2, \ldots, 5$ & 0.516 & 0.258 & 0.129 & 0.065 & 0.032 \\
\hline
\end{tabular}

The weights for the considered options for ordering the private indicators of commercial seaports at $\mathrm{I}=5$ are given in the Table I.

TABLE I. WEIGHTS FOR THE COMPONENTS OF THE TRADE SEAPORT `

\section{CONCLUSION}

The proposed model for the comparative assessment of commercial seaports, based on a set of indicators of the targeted relevance of these ports to the needs of participants in global transport and logistics processes, can be used in the decision support systems of the management bodies of these participants. In particular, it can be used to justify decisions on the development of port logistics infrastructure, as well as to attract investment in its development. The approach to comparative assessment of commercial seaports implemented in the model is well in line with the adopted system of their expertise. The principle of maximum entropy, which is the basis for determining the relative importance of particular characteristics of ports, provides a certain objectivity to the results of their comparative assessment taking into account the typical information uncertainty.

\section{REFERENCES}

[1] Afanasenko I., Borisova V. Economic Logistics. - St. Petersburg: Peter, 2012. $432 \mathrm{p}$.

[2] James R. Stock, Douglas M. Lambert. Strategic Logistics Management. 4th ed., 2005, $797 \mathrm{p}$.

[3] Evgenii. G. Anisimov, Murat R. Gapov, Evgeniia.S. Rodionova, Tatiana Saurenko The Model for Determining Rational Inventory in Occasional Demand Supply Chains// International Journal of Supply Chain Management V 8 № 1 (2019). - P.p. 86 - 89.

[4] O.D. Protsenko, I.O. Protsenko, Logistics and Supply Chain Management - A Look into the Future. Macroeconomic aspect. Moscow: Publishing House "Delo" of the Russian Academy of National Economy and Public Administration, 2012. $192 \mathrm{p}$

[5] Monios J. The role of inland terminal development in the hinterland access strategies of Spanish ports / J. Monios // Research in Transportation Economics. —2011. - Is.33. - Pp.59-66.

[6] Flecks J. Terminal capacities as a competitive factor: new forecasts for container shipping / J. Flecks. - Hamburg: Hypoverinsbank, Global Shipping Division, 2008. - 15p.

[7] Oliver D. Rethinking the port / D. Oliver, B. Slack // Environment \& Planning A. -2006. -Is.38. -Pp.1409-1427.

[8] Ilin, I., Levina, A., Abran, A., Iliashenko, O. (2017). Measurement of enterprise architecture (EA) from an IT perspective: Research gaps and measurement avenues. Paper presented at the ACM International 
Conference Proceeding Series, Part F131936, 232-243. doi: $10.1145 / 3143434.3143457$

[9] Levina, A.I., Dubgorn, A.S., Iliashenko, O.Y. Internet of things within the service architecture of intelligent transport systems (2018) Proceedings - 2017 European Conference on Electrical Engineering and Computer Science, EECS 2017, pp. 351-355. DOI: 10.1109/EECS.2017.72

[10] Saurenko T., Anisimov E., Anisimov V., Levina A. Comparing Investment Projects of Innovative Developing Strategies of Municipalities, Based on a Set of indicators // MATEC Web of Conferences: "International Science Conference SPbWOSCE-2017 "Business Technologies for Sustainable Urban Development"" 2018. P. 01038.

[11] Jaynes E. T. Information Theory and Statistical Mechanics // Physical Review. Series II. 1957. Vol. 106 № 4. P. 620 -630.

[12] Ilin, I., Kalinina, O., Iliashenko, O., Levina, A. Sustainable Urban Development as a Driver of Safety System Development of the Urban Underground (2016) Procedia Engineering, 165, pp. 1673-1682. DOI: 10.1016/j.proeng.2016.11.909

[13] Orlova, V., Ilin, I., Shirokova, S. Management of port industrial complex development: Environmental and project dimensions (2018) MATEC Web of Conferences, 193, 05055. DOI: 10.1051/matecconf/201819305055

[14] Anisimov V.G., Zegzhda P.D., Anisimov E.G., Saurenko T.N., Prisyazhnyuk S.P. Indices of the Effectiveness of Information Protection in an Information Interaction System for Controlling Complex Distributed Organizational Objects // Automatic Control and Computer Sciences. 2017. Vol. 51. № 8. P. 824-828.

[15] Fishburn Peter C. (1988), Nonlinear Preference and Utility Theory. Baltimore, Md.: Johns Hopkins University Press.

[16] Anisimov V.G., Anisimov E.G., Saurenko T.N., Sonkin M.A. The Model and the Planning Method of Volume and Variety Assessment of Innovative Products in an Industrial Enterprise // Journal of Physics: Conference Series . 2017. Vol. 803. № 1. P. 012006. doi.org/10.1088/1742-6596/803/1/012006. 